\title{
Activation of host constitutive immune defence by an intestinal trypanosome parasite of bumble bees
}

5 MJF Brown $^{1,2}$, Y Moret ${ }^{1,3}$ \& P Schmid-Hempel ${ }^{1}$

${ }^{1}$ Ecology and Evolution, ETH-Zürich, ETH-Zentrum NW, CH-8092 Zürich, Switzerland

${ }^{2}$ Department of Zoology, Trinity College Dublin, Dublin 2, Ireland (current

10 address)

${ }^{3}$ Department of Animal and Plant Sciences, University of Sheffield, Western Bank, Sheffield, S10 2TN, UK (current address)

Running title: Invertebrate immune response to gut infection

15

Corresponding author: $\quad$ Mark J F Brown

Department of Zoology, Trinity College Dublin,

Dublin 2

Ireland

20

Email: mabrown@tcd.ie

Tel: +353 (0)1 6081627

Fax: +353 (0)1 6778094 


\section{Summary}

Many parasites have to survive the harsh environment of insect guts to complete their life-cycle. Important parasites of man and animals pass part of their life cycle

5 in insect guts and hence understanding how insects protect themselves against such parasites has immediate practical implications. Previously, such protection has been thought to consist mainly of mechanical structures and the action of lectins.

However, recently it has become apparent that gut infections may interact with the host immune system in more complex ways. Here, using bumble bees, Bombus

10 terrestris and their non-invasive gut trypanosome, Crithidia bombi, as a model system we investigated the effects of parasitic infection, host resources and the duration of infections on the host immune system. We found that infection doubled standing levels of immune defence in the haemolymph (the constitutive proPhenoloxidase system), which is used as a first, general defence against parasites.

15 However, the physical separation of the parasite from the haemolymph suggests the presence of a messenger system between the gut and the genes that control the proPhenoloxidase system. Surprisingly, we found no direct effect of host resource$\underline{\text { stress }}$ or duration of the infection on the immune system. Our results suggest a novel and tactical response of insects to gut infections, demonstrating the complexity of 20 such host-parasite systems.

Keywords: trypanosomes, Crithidia bombi, bumble bees, Bombus terrestris, immune response, pro-Phenoloxidase system 


\section{Introduction}

Many parasites, including species of Trypanosoma, Crithidia, Leishmania, and Plasmodium, and filarial nematodes, must overcome the inhospitable environment

5 of the insect gut for successful reproduction and transmission (Kaslow \& Welburn, 1996). Given the major impact that such parasites can have on human and animal health, understanding how insects defend themselves against such parasites and prevent the establishment of infections is important from both a pure and applied perspective. The main defences of insects against such parasites are thought to be

10 lectins, the peritrophic matrix, lysis, and melanisation and encapsulation above the basal lamina of the gut (reviewed in Kaslow \& Welburn (1996)). Recent work, however, suggests that interactions between gut parasites and the invertebrate immune system may be more complex than previously suspected (Kaaya, Flyg \& Boman, 1987; Richman, et al., 1997; Lowenberger, et al., 1999; Boulanger, et al.,

15 2001; Hao, et al., 2001; Boulanger, et al., 2002).

Invertebrates possess an innate immune system, which has been the focus of much recent study (for reviews, see Hoffmann, Reichhart \& Hetru (1996); Hoffmann \& Reichhart, (1997); Hoffmann, et al. (1999)). It is based on different types of

20 haemocytes that are involved in (i) recognition of non-self surfaces, (ii) the organization of the immune response and, (iii) in nodule formation and encapsulation (Rattclife \& Rowley, 1979; Gupta, 1991). Invertebrates also produce anti-microbial substances, lectins, and other immune factors, such as lysozymes. In 
addition, the phenoloxidase activating system plays a pivotal role in the organisation and effectiveness of immune defence (Söderhall \& Cerenius, 1998).

Functionally, the invertebrate immune response can, therefore, be broken down into

5 two main elements, a constitutive and an inducible part (Hultmark, 1993; Hoffmann, et al., 1996; Söderhall \& Cerenius, 1998). Although the distinction is not always clear-cut and the terminology is not universally accepted, we here call constitutive responses those that utilize or activate immune factors that are present without previous contact with a parasite. Typically, in insects these are the circulating

10 haemocytes and the pro-Phenoloxidase system. Inducible responses, in contrast, rely on the de novo synthesis of anti-parasite factors, e.g., anti-microbial peptides, upon recognition of an appropriate antigenic signal. Constitutive responses provide a first line of defence effective against a broad spectrum of parasites (i.e., they are nonspecific), while coexisting with the inducible responses that provide a second, more

15 specific (i.e., effective against a narrow range of parasites) defence (Hultmark, 1993; Brey \& Hultmark, 1998).

The application of evolutionary concepts demonstrated that the invertebrate immune system is costly to evolve (Kraaijeveld \& Godfray, 1997) and utilize (Moret \&

20 Schmid-Hempel, 2000). In consequence we would expect induction of immune defences, and levels of constitutive response to be appropriate to the threat of parasitism. Indeed, the induction of anti-bacterial peptides has been shown to be specific, with different types of pathogen inducing the production of different peptides (Lemaitre, Reichhart \& Hoffmann, 1997; Engstrom, 1999). Furthermore, 
recent work suggests that invertebrates can alter the constitutive defence response of their offspring with respect to current levels of perceived parasite threat (Moret \& Schmid-Hempel, 2001), and, similarly, that host populations can vary the constitutive defence according to population density, which acts as a correlate for

5 the threat of infections (Wilson \& Reeson, 1998; Barnes \& Siva-Jothy, 2000; Wilson, Cotter, Reeson, et al., 2001).

Apart from the perceived risk of infection, host condition and environmental stress, e.g., resource limitation, temperature, and humidity, are well-known factors that

10 explain variation in the level of the constitutive immune response (e.g., Ferguson \& Read (2002)). As a consequence, otherwise benign parasites may have a large impact when their host is stressed (Jokela, et al., 1999; Brown, Loosli \& SchmidHempel, 2000), and consequently allocation of resources to immune function and the ability to resist stress may trade-off against each other.

15

Here we examine how the non-invasive, intestinal trypanosome gut parasite, Crithidia bombi, affects the immune system of its host, the bumble bee Bombus terrestris, and how this effect is moderated by environmental stress. C. bombi has a high prevalence in bumble bees (Shykoff \& Schmid-Hempel, 1991c). The life cycle

20 is simple - transmission stages (amastigotes and choanomastigotes; personal observation) are ingested from bumble bee faeces and then pass into the hindgut. New transmission stages are released into the host's faeces starting about 3-4 days post-infection (Schmid-Hempel \& Schmid-Hempel, 1993). Several studies, using both cross-infection experiments and genetic analyses, demonstrate strong genetic 
interactions between the parasite and its host (Shykoff \& Schmid-Hempel, 1991a, b; Schmid-Hempel \& Schmid-Hempel, 1993; Imhoof \& Schmid-Hempel, 1998; Schmid-Hempel, et al., 1999). While normally benign, in food-stressed bees the parasite may impose a 50\% increase in background mortality rate (Brown, et al., $52000)$.

We examined the effects of infection, food-stress and the duration of these treatments (days post-inoculation) on immune parameters of the bumble bee host. As the parasite is non-invasive and thus restricted to the gut lumen, we expected

10 that the infection would have a marginal or no effect on the immune responses located in the haemolymph, such as the pro-Phenoloxidase activating system or the number of circulating haemocytes. In contrast, we predicted that under food-stress the parasite should cause a decrease in the level of the constitutive immune defence due to the cost of the use of host's resource by the parasite, which would be hard to

15 compensate for under stressful conditions. We also predicted that this decrease of constitutive defence should be more marked the longer the duration of the infection. Surprisingly, we found that infection by this non-invasive parasite produced an increase in the constitutive pro-Phenoloxidase immune system present in the haemolymph, a previously unreported aspect of the invertebrate immune function in

20 this particular in vivo context. However, in contrast to other recent studies (Boulanger, et al., 2001; Hao, et al., 2001; Boulanger, et al., 2002), we found no evidence for a similar increase in the production of inducible antibacterial peptides.

\section{Materials and Methods}


Bees for the experiment were taken from three, unrelated laboratory-reared colonies of $B$. terrestris, first-generation descendants of queens collected in the field around Zürich, Switzerland in spring 2000. Prior to the experiment, bees were reared at

$5 \quad 29^{\circ} \mathrm{C}$ and $60 \%$ relative humidity and supplied with ad libitum pollen and sugar water.

Bees from each colony were randomly assigned to one of 8 treatment groups, for a total of 10 bees per group. Treatments were as follows: (A) control vs. infected, to

10 test for the effect of Crithidia bombi infection on the immune system of the bees, (B) pollen vs. no pollen, to test for the effect of resource-stress (pollen is needed for both ovary and fat body development, with the fat body playing an essential role in the invertebrate immune system), (C) measurement after 7 days vs. 14 days, to test for the effect of the duration of infection, as well as a simple age effect (see Table 1

15 for the full crossed design). Bees in the infected treatment were starved for 3-4 hours and then fed a standardised inoculum of 5000 C. bombi cells (from at least five different parasite strains) in sugar water. Control bees were similarly starved, but then fed normal sugar water. Bees in the pollen treatment were kept with ad libitum pollen and sugar water for the duration of the treatment, while bees in the no

20 pollen treatment had their pollen source removed at day five of the experiment and were then kept on sugar water. Bees in the 7 days treatment were frozen on the 7 th day of the experiment for measurement of the experimental variables (see below), and bees in the 14 days treatment were frozen on the 14th (and last) day of the experiment. 
We measured five variables in each experimental animal - haemocyte concentration, antibacterial activity, phenoloxidase activity, fat body size and ovary development. Of these, the first four are directly relevant to immune function (the

5 insect fat body is functionally analogous to the vertebrate liver, and responsible for the production of antibacterial peptides), whilst ovary development is a proxy for reproductive capacity and known to trade-off with allocation of resources to the fat body. Each worker was bled to measure the haemocyte concentration, the antibacterial activity and the phenoloxidase (PO) activity of their haemolymph. For

10 this, each insect was chilled $10 \mathrm{~min}$ on ice and the pleural membrane between the $5^{\text {th }}$ and the $6^{\text {th }}$ sternite of the abdomen was punctured with a sterile hypodermic needle. The droplet of haemolymph that came out of the wound was collected into a sterile and pre-chilled glass capillary. For each insect, $10 \mu \mathrm{l}$ of haemolymph was collected and flushed into a 1.5-ml Eppendorf tube containing $50 \mu \mathrm{l}$ of cold sodium

15 cacodilate/CaCl2 buffer (0.01 M Na-Cac, 0.005 M CaCl2, pH 6.5). Bees were immediately freeze-killed and stored at $-80^{\circ} \mathrm{C}$ for remaining analyses (see below). A 10- $\mu$ l sample of the diluted haemolymph was immediately used for the estimation of the haemocyte concentration using an improved Neubauer haemocytometer. Another 10 - $\mu$ l sample was kept in a $0.5-\mathrm{ml}$ Eppendorf tube and stored at $-20^{\circ} \mathrm{C}$ for

20 later examination of the antibacterial activity using a zone-of-inhibition test. This test consists of adding a $2 \mu \mathrm{l}$ drop of haemolymph to a plate of bacteria and measuring the radius of the zone where antibacterial peptides in the haemolymph inhibit bacterial growth. The methods for this test were the same as described in Moret \& Schmid-Hempel (2000) except that the assay was performed using 
haemolymph diluted 6 times with sodium cacodilate/ $\mathrm{CaCl}_{2}$ buffer. The rest of the haemolymph solution was diluted with an additional volume of $100 \mu \mathrm{l}$ of cold sodium cacodilate $/ \mathrm{CaCl} 2$ buffer and immediately stored at $-80^{\circ} \mathrm{C}$ for later measurement of the PO activity. For the PO activity assay, samples of frozen

5 haemolymph solution (dilution 1/21; haemolymph/sodium cacodilate/CaCl2 buffer) were thawed on ice and then centrifuged (6500 r.p.m., 15 min, $4^{\circ} \mathrm{C}$ ). The supernatant was removed and vortexed, after which $20 \mu \mathrm{l}$ of the supernatant was added to a microplate well containing $140 \mu \mathrm{l}$ of distilled water, $20 \mu \mathrm{l}$ of Phosphate Buffer Saline (PBS: 8.74 g NaCl; 1.78 g Na2HPO4, 2H2O; 1000 ml distilled water;

$10 \mathrm{pH}$ 6.5) and $20 \mu \mathrm{l}$ of L-Dopa solution (4 mg per millilitre of distilled water). The reaction was allowed to proceed at $30^{\circ} \mathrm{C}$ in a microplate reader (SpectraMAX340PC) for $20 \mathrm{~min}$. Readings were taken every 10 seconds at $480 \mathrm{~nm}$ and analysed using SOFTmax ${ }^{\circledR P R O} 3.1$ software. The enzyme activity was measured as the slope of the reaction curves during the linear phase of the reaction (between 10 to

1520 min after the reaction mix was made; Y. Moret, personal observation).

Frozen bees were dissected blind with respect to treatment and we recorded presence/absence of a C. bombi infection (under x400 magnification), ovary development (the mean length of the three terminal oocytes), body size (length of 20 the radial cell of the right forewing), and fat body size. To measure the amount of fat present we followed the protocol of Ellers (1996). For this, the abdomen was dried at $70^{\circ} \mathrm{C}$ for 3 days and then weighed with a precision balance. The abdomen was then placed in $2 \mathrm{ml}$ of ether for 24 hrs to extract the fat. After rinsing with fresh ether, the abdomen was again dried for 3 days and weighed again. The amount of fat 
is indicated by the difference between these two measures. We divided fat mass by body size to get an estimate of relative fat body size for use in the statistical $\underline{\text { analyses }}$

5 The ideal analysis for this experiment would be a 4-way MANOVA with colony as a random factor, and infection, pollen, and time treatments as fixed factors. Unfortunately, the data failed to meet the assumptions for such an analysis (the structure of variation across treatment groups made it impossible to transform the data to meet the assumptions of homogeneity and normality when colony was

10 included in the design). Consequently, we took two complementary approaches to analyse these data. Firstly, using the untransformed data, we conducted 4-way MANOVA analyses for each of the variables independently (that is, using the error terms assigned for MANOVA univariate tests). We followed these analyses with 3way MANOVAs on the transformed data for each colony individually

15 (phenoloxidase activity was square-root transformed to meet the assumptions of the analyses). Because the results of the two analyses were qualitatively the same, we report here the results of the 4-way analyses. The untransformed data are presented in Table 2.

20 Of the five dependent variables, anti-bacterial activity and oocyte length could not be transformed to meet the assumptions of MANOVA analyses, due to a large number of zero values, and the complexity of the experiment prevented a comparable non-parametric analysis. Consequently, to analyse these data we converted the variables into $0 / 1$ categorical variables (' 0 ' = no activity or no egg 
development, ' 1 ’ = activity or egg development) and entered them into logistic regression analyses. We used a forward stepwise likelihood ratio design, with colony given deviation coding and infection, food and life treatments coded as indicator variables.

All analyses were done on SPSS 6.1.1 and SPSS 10 for the Macintosh, and for the MANOVA we report the results of the multivariate and univariate tests (all $P$-values are two-tailed). Data are reported as mean \pm standard deviation.

\section{Results}

Direct effects of infection

Infection by Crithidia bombi had a positive effect on the level of phenoloxidase activity, with infected bees having, on average, twice the level of activity of

15 uninfected bees (MANOVA, $\mathrm{F}_{1,2}=27.3, \mathrm{P}=$ 0.035; Fig 1). In contrast, infection had no direct effect on the haemocyte concentration of bees $\left(F_{1,2}=7.83, P=0.108\right)$, their relative fat content $\left(\mathrm{F}_{1,2}=1.23, \mathrm{P}=0.383\right)$, anti-bacterial activity (control bees, $\underline{21 / 118 \text { exhibited activity, } 1.5 \pm 3.60 \text {; infected bees, } 26 / 116 \text { exhibited activity, } 2.4 \pm}$ 4.72; no significant regression model, Score $=2.708, \mathrm{P}=0.1$ ) or ovary development 20 (not in the final model, Score $=0.358, \mathrm{P}=0.550$ ).

Direct effects of food deprivation 
Surprisingly, the food treatment (ad libitum pollen vs. no pollen) had no direct effect on haemocytes $\left(\mathrm{F}_{1,2}=0.06, \mathrm{P}=0.831\right)$, phenoloxidase activity $\left(\mathrm{F}_{1,2}=6.22, \mathrm{P}\right.$ $=0.13)$, fat content $\left(F_{1,2}=0.00, P=0.98\right)$ or anti-bacterial activity of the experimental animals (pollen-fed bees, 22/115 exhibited activity, $2.0 \pm 4.45$; pollen-

5 starved bees, 25/119 exhibited activity, 1.9 \pm 3.97; no significant regression model, Score $=0.114, \mathrm{P}=0.736)$. As expected, pollen-starved bees were less likely to exhibit ovary development (Wald-statistic $=8.749, \mathrm{DF}=1, \mathrm{P}=0.003)$.

\section{Direct effects of duration of the experiment}

Similarly, the duration of the experiment did not affect haemocytes $\left(\mathrm{F}_{1,2}=1.43, \mathrm{P}=\right.$ 0.355), phenoloxidase activity $\left(\mathrm{F}_{1,2}=1.28, \mathrm{P}=0.376\right)$, fat content $\left(\mathrm{F}_{1,2}=0.61, \mathrm{P}=\right.$ 0.517) or anti-bacterial activity of the experimental animals (7-day bees, 22/120 exhibited activity, $1.9 \pm 4.33$; 14 -day bees, 25/114 exhibited activity, $2.1 \pm 4.09$; no

15 significant regression model, Score $=0.082, \mathrm{P}=0.774)$. In contrast, bees from day 14 of the experiment were less likely to exhibit ovary development (Wald-statistic = 8.749, $\mathrm{DF}=1, \mathrm{P}=0.003)$.

\section{Direct effects of colony identity}

There were significant differences among colonies in their haemocyte concentrations (mean \pm SE of counts: colony $1=50 \pm 4.3$, colony $2=38 \pm 3.3$, colony $\left.3=37 \pm 2.9 ; F_{2,180}=4.91, P=0.008\right)$. Otherwise, colony identity only had a direct effect on ovary development, with bees from colonies 1 and 3 being more 
likely to have developed ovaries than bees from colony 2 (Wald-statistic $=25.833$, $\mathrm{DF}=2, \mathrm{P}<0.001)$

Interactions among experimental treatments

There were no significant 2-way interactions between the infection treatment and any other treatment. This indicates that, regardless of colony identity, duration of the infection, or nutrient intake (ad libitum pollen vs. pollen-starved), all bees responded similarly to the infection.

The only significant 2-way interaction was between colony identity and the duration treatment (Figure 2). There were significant effects on haemocyte concentration $\left(F_{2,180}=6.72, P=0.002\right)$, phenoloxidase activity $\left(F_{2,185}=8.09, P<0.001\right)$, and relative fat content $\left(F_{2,180}=4.43, P=0.013\right)$. These effects were due to a larger

15 decline in haemocyte concentration across time in colony 1 vs. colonies 2 and 3 (Fig. 2a), an increase in phenoloxidase activity across time in colonies 1 and 2 vs. a decrease in colony 3 (Fig. 2b), and an increase in relative fat content across time in colonies 1 and 3 vs. a decrease in colony 2 (Fig. 2c).

\section{Discussion}

The main result from our experiment is that a non-invasive gut parasite effectively doubled the standing-level of immune response in the haemolymph of infected bees as measured by the activity of the pro-Phenoloxidase system. Previous reports 
suggest that trypanosome parasites are able to activate the pro-Phenoloxidase system in haemolymph upon direct contact in vitro and that this activation is crucial to contain the infection (Nigam, et al., 1997). However, here the in vivo increase in phenoloxidase activity was found in the samples taken from the host haemolymph,

5 and was thus physically separated from the site of infection. Infection had no direct effect on any of the other measures, which was in line with previous work (Brown, et al., 2000).

Three separate lines of evidence demonstrate that C. bombi is indeed a non-invasive

10 parasite. 1) in over ten years of study in this system, C. bombi parasites have never been seen to break through the host gut and invade the haemolymph (personal observations). 2) during this study we microscopically examined the haemolymph of infected animals for our haemocyte counts and never observed parasites or their encapsulated remains. 3) the absence of an anti-bacterial response to infection,

15 which we would expect if the gut wall was broken by the passaging of parasites, again indicates no invasion of the body cavity. Consequently, our results suggest the existence of a messenger system between the gut and the genes that control proPhenoloxidase activity in the haemolymph, as has recently been suggested for the inducible immune system of invertebrates (Hao, et al., 2001).

Given the specific and inducible nature of anti-bacterial peptides, the absence of an effect of infection on antibacterial activity is perhaps unsurprising. This result is unlikely to be due to a lack of sensitivity in the test, as (i) $20 \%$ of the study animals showed measurable antibacterial activity (see Results) and (ii) previous studies 
using this test have found statistically significant differences between induced and control bees in antibacterial activity (Moret \& Schmid-Hempel, 2000, 2001) However, our results differ sharply from those of Boulanger, et al. (2001) and Boulanger, et al. (2002), who found specific production of inducible anti-microbial

5 peptides both when Drosophila melanogaster were infected per os by C. bombi, and when Glossina mortisans were infected by Trypanosoma brucei brucei. These differences may reflect the parasite pressure felt by the different species. The proPhenoloxidase system acts as a general, non-specific protection and may be energetically cheaper and more efficient than the production of specific peptides

10 when the particular threat cannot be predicted. In contrast, Boulanger, et al. (2002) suggested that the presence of numerous bacterial symbionts in the digestive tract of tsetse flies might explain the induction of anti-microbial peptides in their experiment. Whether D. melanogaster or G. mortisans produce an increase in the constitutive pro-Phenoloxidase system after infection remains unknown.

The general absence of a direct effect of resource-stress on measures of the immune system suggests either that immune function is a priority for resource allocation, or that bees were simply not stressed enough. Given that pollen-starved bees exhibited less ovary development, and that previous work also suggested priority allocation of 20 resources to immune function over survival (Moret \& Schmid-Hempel, 2000), we believe that the former explanation is most likely. In one colony, pollen-starvation did reduce phenoloxidase activity when compared to control bees of the same age, suggesting that a reduction in resource-availability can decrease the immune function of invertebrates, as has also recently been found in the mealworm beetle, 
Tenebrio molitor (Siva-Jothy \& Thompson, in press). The magnitude and occurrence of this effect probably depends upon the initial host condition, as has been seen in vertebrates (Nordling, et al., 1998; Fair, Hansen \& Ricklefs, 1999).

5 We examined the effect of the duration of an infection on immune function by sacrificing host and control bees at 7 and 14 days post-infection. In general, longer infections produced a greater increase in the standing immune response (as shown by increased phenoloxidase activity), although this was true for only 2 of the 3 colonies (Fig. 2b). While infection had no effect on haemocyte concentration, the

10 longer-lived and therefore older bees had a reduced haemocyte complement, reflecting a general effect of age on the immune function of individuals (Fig 2a). This matches results from previous work in bumble bees, where encapsulation ability and haemocyte number also declined with increasing age (Doums, et al., 2002). A surprising result of the life treatment was the effect that it had on fat-body

15 size. The increase in fat body size from days 7 to 14 seen in 2 out of 3 colonies suggests that bees may be re-allocating resources from the ovary (which regressed over time) to the fat body (Fig 2c).

To conclude, we have demonstrated a novel response in vivo of the constitutive

20 invertebrate immune system to infection by a non-invasive, intestinal parasite. This adds to recent evidence that such infections can induce the production of antibacterial peptides (Boulanger, et al., 2001; Hao, et al., 2001; Boulanger, et al., 2002). There is indeed accumulating evidence that local infection of the gut triggers a systemic immune response and, vice versa, a systemic 
response induces a local response (Lehane et al., PNAS 1997, Nakajima et al. Insect Biochemistry and Molecular Biology 2001). It has been suspected that immune messengers connecting gut tissue and the fat body (a prime site of the immune system) inlcude nitric oxide or cytokine-like molecules (Hao, et al., 2001;

5 , perhaps in the form of TNF-homologues as recently discovered in Drosophila (Kanda et al. 2002; Moreno et al. 2002). Hence, the invertebrate immune system appears to play an important rolealso in the control of intestinal parasites. The exact function of the enhanced immune response to Crithidia infection remains to be determined.

10

\section{Acknowledgements}

We would like to thank Roland Loosli for technical assistance. This work was made possible by a grant from the Swiss NSF (nr. 31-49040.02 to PSH) and a contribution by the EU (TMR / BBW nr 95.0575). The manuscript was improved by comments

15 from R. S. Phillips and an anonymous reviewer. 


\section{References}

Barnes, A. I. \& Siva-Jothy, M. T. (2000). Density-dependent prophylaxis in the mealworm beetle Tenebrio molitor L-(Coleoptera : Tenebrionidae): cuticular

5 melanization is an indicator of investment in immunity. Proceedings of the Royal Society Biological Sciences Series B 267, 177-182.

Boulanger, N., Brun, R., Ehret-Sabatier, L., Kunz, C. \& Bulet, P. (2002).

Immunopeptides in the defense reactions of Glossina morsitans to bacterial and

10 Trypanosoma brucei brucei infections. Insect Biochemistry and Molecular Biology 32, 369-375.

Boulanger, N., Ehret-Sabatier, L., Brun, R., Zachary, D., Bulet, P. \& Imler, J.-L. (2001). Immune response of Drosophila melanogaster to infection with the

15 flagellate parasite Crithidia spp. Insect Biochemistry and Molecular Biology 31, 129-137.

Brey, P. T. \& Hultmark, D. (1998). Molecular Mechanisms of Immune Response in Insects. Chapman \& Hall, London.

Brown, M. J. F., Loosli, R. \& Schmid-Hempel, P. (2000). Condition-dependent expression of virulence in a trypanosome infecting bumblebees. Oikos 91, 421-427. 
Doums, C., Moret, Y., Benelli, E. \& Schmid-Hempel, P. (2002). Senescence of immune defence in Bombus workers. Ecological Entomology 27, 138-144.

Ellers, J. (1996). Fat and eggs: an alternative method to measure the trade-off

5 between survival and reproduction in insect parasitoids. Netherlands Journal of Zoology 46, 227-235.

Engstrom, Y. (1999). Induction and regulation of antimicrobial peptides in Drosophila. Developmental and Comparative Immunology 23, 345-358.

Fair, J. M., Hansen, E. S. \& Ricklefs, R. E. (1999). Growth, developmental stability and immune response in juvenile Japanese quails (Coturnix coturnix japonica). Proceedings of the Royal Society Biological Sciences Series B 266, 1735-1742.

15 Ferguson, H. M. \& Read, A. F. (2002) Why is the effect of malaria parasites on mosquito survival still unresolved? Trends in Parasitology 18, 256-261.

Gupta, A. P. (1991). Immunology of Insects and Other Arthropods. In Insect immunocytes and other hemocytes: Role of cellular and humoral immunity. (ed. 20 Gupta, A. P.), pp. 133-167, CRC Press, Boca Raton, FL.

Hao, Z., Kasumba, I., Lehane, M. J., Gibson, W. C., Kwon, J. \& Aksoy, S. (2001). Tsetse immune response and trypanosome transmission: Implications for the 
development of tsetse-based strategies to reduce trypanosomiasis. Proceedings of the National Academy of Sciences USA 98, 12648-12653.

Hoffmann, J. A. \& Reichhart, J. M. (1997). Drosophila immunity. Trends in Cell 5 Biology 7, 309-316.

Hoffmann, J. A., Reichhart, J. M. \& Hetru, C. (1996). Innate immunity in higher insects. Current Opinion in Immunology 8, 8-13.

10 Hoffmann, J. A., Kafatos, F. C., Janeway, C. A. \& Ezekowitz, R. A. B. (1999). Phylogenetic perspectives in innate immunity. Science 284, 1313-1318.

Hultmark, D. (1993). Immune reactions in Drosophila and other insects: a model for innate immunity. Trends in Genetics 9, 178-183.

15

Imhoof, B. \& Schmid-Hempel, P. (1998). Patterns of local adaptation of a protozoan parasite to its bumblebee host. Oikos 82, 59-65.

Jokela, J., Lively, C. M., Taskinen, J. \& Peters, A. D. (1999). Effect of starvation on 20 parasite-induced mortality in a freshwater snail (Potamopyrgus antipodarum). Oecologia 119, 320-325. 
Kaaya, G. P., Flyg, C. \& Boman, H. G. (1987). Induction of cecropin and attackinlike antibacterial factors in the hemolymph of Glossina mortisans mortisans. Insect Biochemistry 17, 309-315.

5 Kaslow, D. C. \& Welburn, S. (1996). Insect-transmitted pathogens in the insect midgut. In Biology of the Insect Midgut (ed. Lehane, M. J. \& Billingsley, P. F.), pp. 432-462, Chapman \& Hall, London.

Kraaijeveld, A. R. \& Godfray, H. C. J. (1997). Trade-off between parasitoid

10 resistance and larval competitive ability in Drosophila melanogaster. Nature 389, 278-280.

Lemaitre, B., Reichhart, J. M. \& Hoffmann, J. A. (1997). Drosophila host defense: Differential induction of antimicrobial peptide genes after infection by various 15 classes of microorganisms. Proceedings of the National Academy of Sciences USA 94, 14614-14619.

Lowenberger, C. A., Kamal, S., Chiles, J., Paskewitz, S., Bulet, P., Hoffmann, J. A. \& Christensen, B. M. (1999). Mosquito-Plasmodium interactions in response to 20 immune activation of the vector. Experimental Parasitology 91, 59-69.

Moret, Y. \& Schmid-Hempel, P. (2000). Survival for immunity: the price of immune system activation for bumblebee workers. Science 290, 1166-1168. 
Moret, Y. \& Schmid-Hempel, P. (2001). Immune defence in bumble-bee offspring. Nature 414, 506.

Nigam, Y., Maudlin, I., Welburn, S. \& Ratcliffe, N. A. (1997). Detection of

5 phenoloxidase activity in the hemolymph of Tsetse flies refractory and susceptible to infection with Trypanosoma brucei rhodesiense. Journal of Inverterbrate Pathology 69, 279-281.

Nordling, D., Andersson, M., Zohari, S. \& Gustafsson, L. (1998). Reproductive

10 effort reduces specific immune response and parasite resistance. Proceedings of the Royal Society of London Series B Biological Sciences 265, 1291-1298.

Rattclife, N. A. \& Rowley, A. F. (1979). Insect Hemocytes: Development, Forms Functions and Techniques. In Role of hemocytes in defence against biological 15 agents (ed. Gupta, A. P.), pp. 331-414, Cambridge University Press, New York.

Richman, A. M., Dimopoulos, G., Seeley, D. \& Kafatos, F. C. (1997). Plasmodium activates the innate immune response of Anopheles gambiae mosquitoes. EMBO Journal 16, 6114-6119.

Schmid-Hempel, P. \& Schmid-Hempel, R. (1993). Transmission of a pathogen in Bombus terrestris, with a note on division of labour in social insects. Behavioral Ecology and Sociobiology 33, 319-327. 
Schmid-Hempel, P., Puhr, K., Kruger, N., Reber, C. \& Schmid-Hempel, R. (1999).

Dynamic and genetic consequences of variation in horizontal transmission for a microparasitic infection. Evolution 53, 426-434.

5 Shykoff, J. A. \& Schmid-Hempel, P. (1991a). Parasites and the advantage of genetic variability within social insect colonies. Proceedings of the Royal Society of London Series B Biological Sciences 243, 55-58.

Shykoff, J. A. \& Schmid-Hempel, P. (1991b). Genetic relatedness and eusociality:

10 Parasite-mediated selection on the genetic composition of groups. Behavioral Ecology and Sociobiology 28, 371-376.

Shykoff, J. A. \& Schmid-Hempel, P. (1991c). Incidence and effects of four parasites in natural populations in bumble bees in Switzerland. Apidologie 22, 117-126.

15

Siva-Jothy, M. \& Thompson, J. J. W. (2002). Short-term nutrient deprivation affects immune function. Physiological Entomology, in press.

Söderhall, K. \& Cerenius, L. (1998). Role of the prophenoloxidase-activating 20 system in invertebrate immunity. Current Opinion in Immunology 10, 23-28.

Wilson, K. \& Reeson, A. F. (1998). Density-dependent prophylaxis: Evidence from Lepidoptera-baculovirus interactions? Ecological Entomology 23, 100-101. 
Wilson, K., Cotter, S. C., Reeson, A. F. \& Pell, J. K. (2001). Melanism and disease resistance in insects. Ecology Letters 4, 637-649. 
Table 1: Experimental design of the infection with C. bombi for each of the 3 colonies of $B$. terrestris. For each colony a group of 10 workers was assigned to one of the 8 treatment groups according to infection treatment (control vs. infected), resource treatment (fed with vs. without pollen) and duration of the infection where 5 the workers were tested for various measures at 7 vs. 14 days post infection.

\begin{tabular}{|c|c|c|}
\hline & Control for infection & Infection with C. bombi \\
\hline Fed with pollen & $\begin{array}{l}\text { Tested at } 7 \text { days post } \\
\text { inoculation }(\mathrm{N}=10)\end{array}$ & $\begin{array}{l}\text { Tested at } 7 \text { days post } \\
\text { inoculation }(\mathrm{N}=10)\end{array}$ \\
\hline & $\begin{array}{l}\text { Tested at } 14 \text { days post } \\
\text { inoculation }(\mathrm{N}=10)\end{array}$ & $\begin{array}{l}\text { Tested at } 14 \text { days post } \\
\text { inoculation }(\mathrm{N}=10)\end{array}$ \\
\hline Starved (without pollen) & $\begin{array}{l}\text { Tested at } 7 \text { days post } \\
\text { inoculation }(\mathrm{N}=10)\end{array}$ & $\begin{array}{l}\text { Tested at } 7 \text { days post } \\
\text { inoculation }(\mathrm{N}=10)\end{array}$ \\
\hline & $\begin{array}{l}\text { Tested at } 14 \text { days post } \\
\text { inoculation }(\mathrm{N}=10)\end{array}$ & $\begin{array}{l}\text { Tested at } 14 \text { days post } \\
\text { inoculation }(\mathrm{N}=10)\end{array}$ \\
\hline
\end{tabular}


Table 2. Mean \pm SE of the five dependent variables haemocyte number, phenoloxidase activity, antibacterial activity, relative fat content (in $\mathrm{mg} / \mathrm{mm}$ ) and oocyte length (in $\mathrm{mm}$ ) for the eight treatment groups by colony. Numbers 1, 2, 3 represent three, unrelated laboratory-reared colonies.

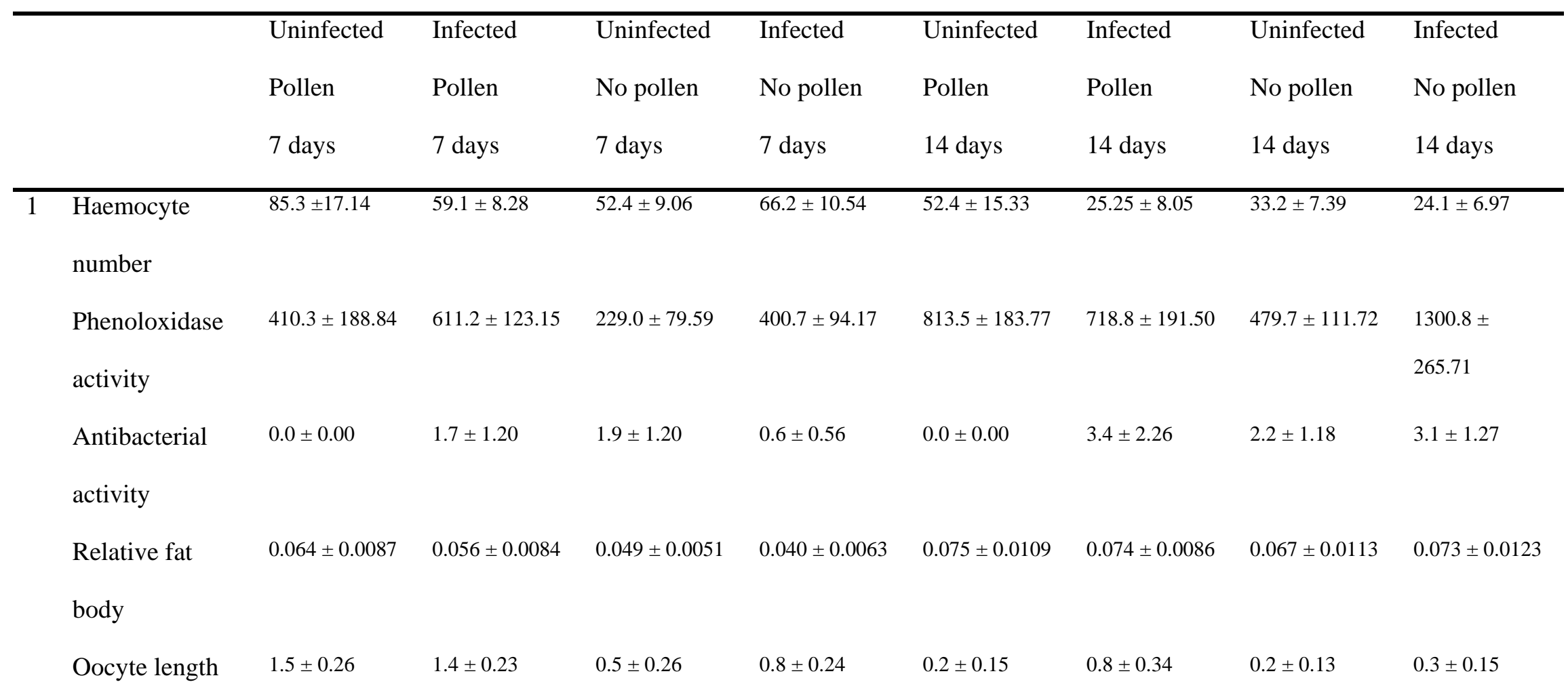




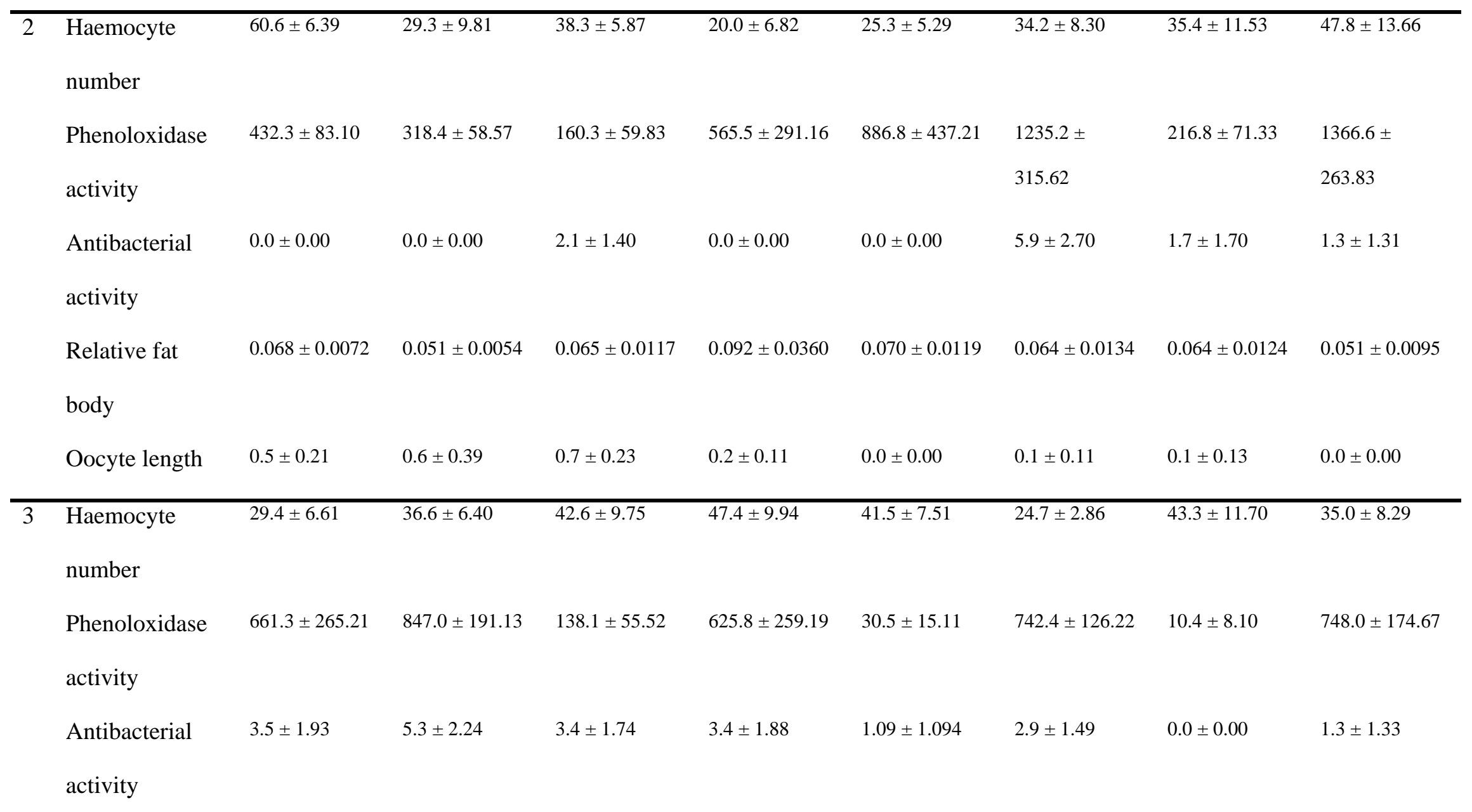




\begin{tabular}{lcccccccc} 
Relative fat & $0.075 \pm 0.0084$ & $0.071 \pm 0.0060$ & $0.060 \pm 0.0071$ & $0.057 \pm 0.0087$ & $0.071 \pm 0.0065$ & $0.071 \pm 0.0077$ & $0.083 \pm 0.0155$ & $0.068 \pm 0.0069$ \\
body & & & & & & & \\
Oocyte length & $2.0 \pm 0.11$ & $1.3 \pm 0.32$ & $1.5 \pm 0.27$ & $1.4 \pm 0.32$ & $0.9 \pm 0.37$ & $1.6 \pm 0.27$ & $0.3 \pm 0.14$ & $0.1 \pm 0.09$ \\
\hline
\end{tabular}


Figure legends

Figure 1. The effect of infection by Crithidia bombi on phenoloxidase activity, across all bees and within each colony (colony number is on the x-axis).

Figure 2. The interaction between colony identity and duration of the experiment on the haemocyte counts, phenoloxidase activity and relative fat content of bees (colony number given is on the $\mathrm{x}$-axis). 
Figure 1

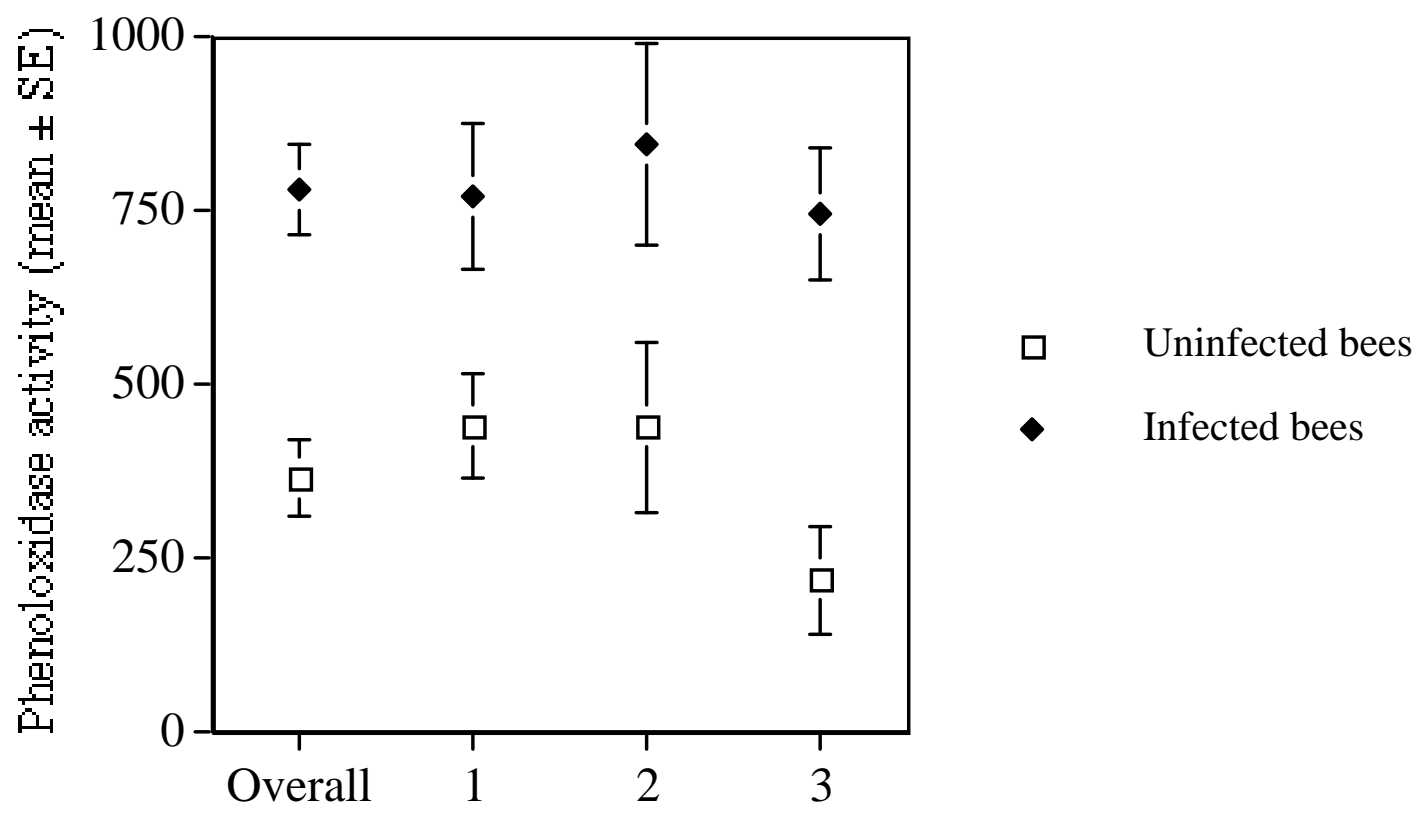


Figure 2a, b

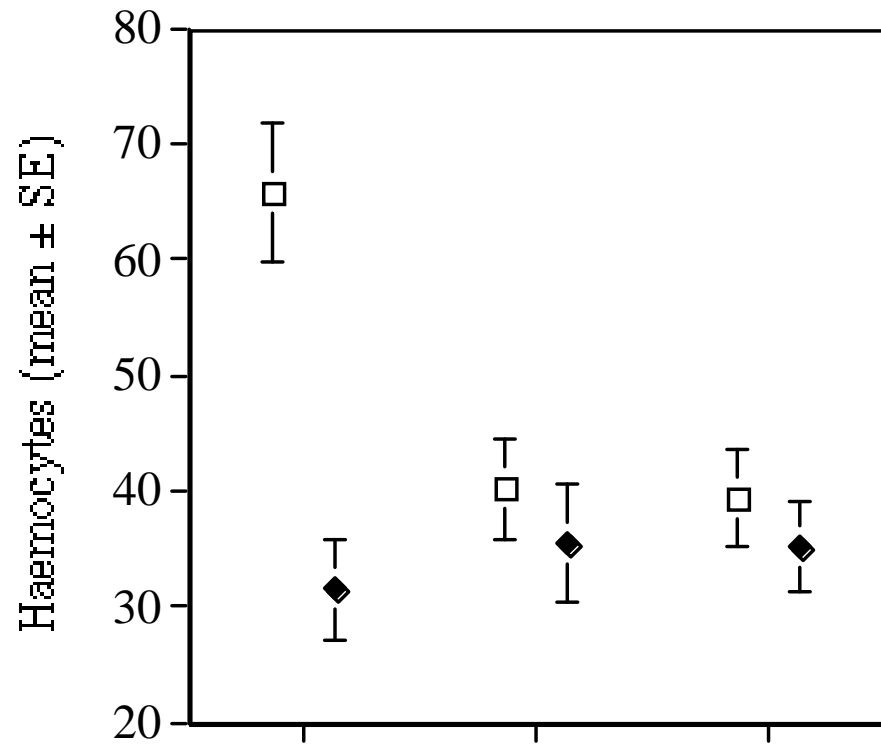

ㅁ 7 days

$\checkmark \quad 14$ days 


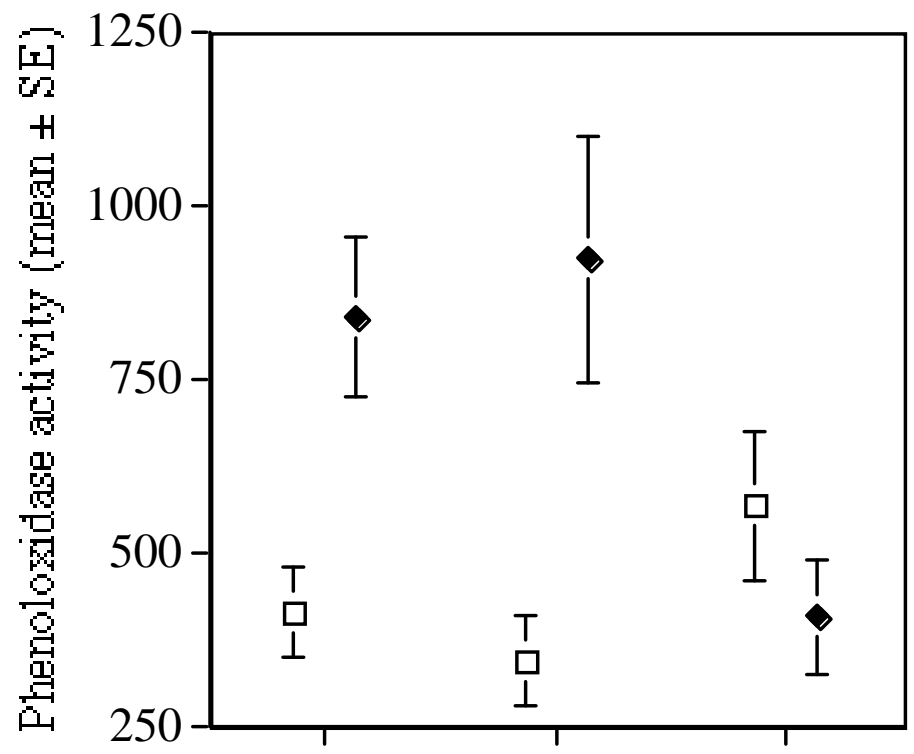

7 days

- 14 days

Figure 2c

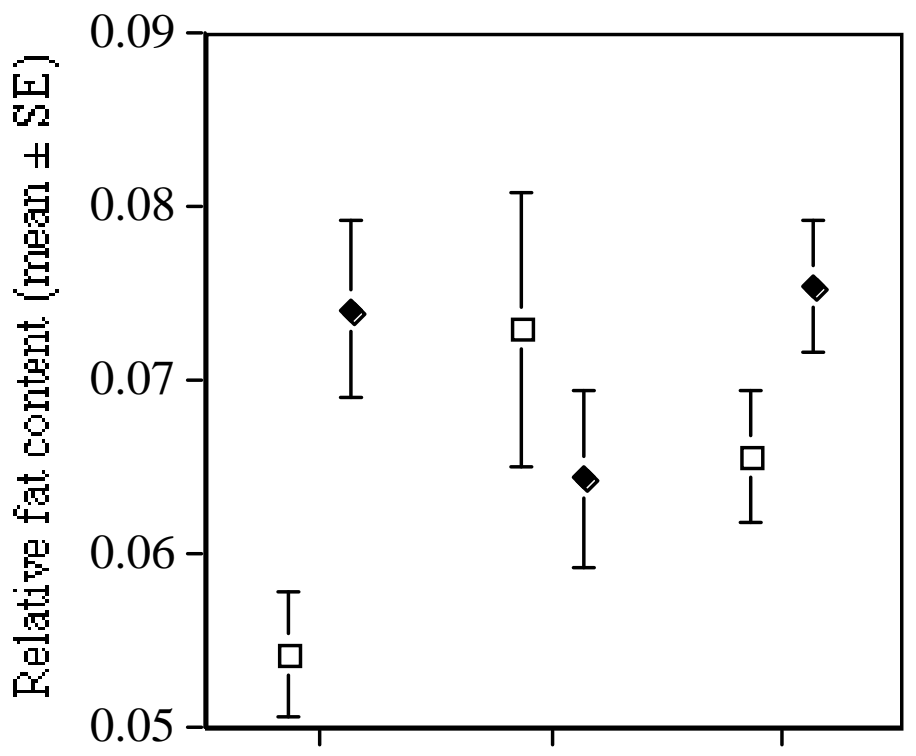

ㅁ 7 days

- 14 days 